\title{
SUPPURATIVE PERICARDITIS DUE TO A PENICILLIN- AND STREPTOMYCIN-RESISTANT STAPHYLOCOCCUS
}

BY

\author{
W. H. P. CANT, K. D. ROBERTS and K. B. ROGERS \\ From the Children's Hospital, Birmingham
}

(RECEIVED FOR PUBLICATION APRIL 15, 1955)

In spite of modern antibiotic therapy, suppurative pericarditis remains a serious condition and the mortality rate is still believed to be in the region of $50 \%$ (d'Abreu, 1953). Aird (1949) states that the mortality by aspiration alone is $100 \%$, by operation alone $50 \%$, but that the mortality from a combination of aspiration and penicillin replacement should be low providing the organism is sensitive to antibiotics.

Treatment by aspiration and antibiotic replacement is likely to be ineffective if there is loculation within the pericardial sac when cardiac compression might occur, and when the antibiotic cannot penetrate into the pockets of loculated pus.

The following case is reported in view of the initial difficulty in diagnosis and the inadequate response to aspiration and replacement therapy, as well as the resistance of the infecting organism to the antibiotics that are usually considered most suitable for intrapericardial instillation. The child's father is a doctor, and this may account for the unusual resistance of the organism, which one could expect to find in a 'hospital infection' rather than in one acquired in the home.

\section{Case Report}

C.W., a girl aged 21 months, was admitted to the Children's Hospital, Birmingham, on June 30, 1954, because of a pyrexia of uncertain origin. She had been ill for five days and was irritable and refusing food; the temperature had been raised from the onset and had reached $102^{\circ} \mathrm{F}$. before admission. She had been given oral penicillin by her own practitioner.

On examination she was seen to be a well nourished, irritable, ill-looking child. A short expiratory grunt was heard with each respiration, but there was no cyanosis. Temperature $102^{\circ} \mathrm{F}$., pulse 120 , respirations 28. No abnormal physical signs could be detected.

A chest radiograph showed no lesion. A leucocytosis was present (see Table). Routine agglutination tests were negative.

The child was treated empirically by a systemic course of chloramphenicol which was begun on July 1. The temperature fell to normal on the sixth day of antibiotic treatment which was continued for a further two days, that is up to July 8.

On July 5 a pericardial friction rub was present, and a chest radiograph at this time showed a large heart shadow and on screening there was feeble pulsation suggestive of a pericardial effusion.

As the child was afebrile at this stage the possibility of a serous effusion or a Fiedler's myocarditis was considered. Pericardial aspiration was not performed until the temperature rose again a week later.

Five days after the chloramphenicol had been discontinued, on July 13, the temperature again rose to $100^{\circ} \mathrm{F}$. The leucocytosis was still present (see Table).

On July 14 the child was still pyrexial and pericardial aspiration was performed via the xiphicostal angle;

TABLE

LEUCOCYTE COUNT

\begin{tabular}{|c|c|c|c|c|c|c|}
\hline \multirow{2}{*}{1954} & \multirow{2}{*}{ Total W.B.C. } & \multirow{2}{*}{ Total Granulocytes } & \multicolumn{2}{|c|}{ Polymorphonuclears } & \multirow{2}{*}{ Metamyelocytes } & \multirow{2}{*}{$\mathrm{Hb}(\mathrm{g} . \%)$} \\
\hline & & & Segmented & Unsegmented & & \\
\hline $\begin{array}{lr}\text { June } & 30 \\
\text { July } & 3 \\
\text { July } & 12 \\
\text { July } & 19\end{array}$ & $\begin{array}{l}19,000 \\
17,700 \\
20,000 \\
25,000\end{array}$ & $\begin{array}{l}11,980 \\
11,859 \\
12,600 \\
16,750\end{array}$ & $\begin{array}{r}9,690 \\
11,328 \\
12,000 \\
16,000\end{array}$ & $\begin{array}{r}1,330 \\
354 \\
400 \\
750\end{array}$ & $\begin{array}{r}760 \\
177 \\
200 \\
0\end{array}$ & $\begin{array}{r}11 \cdot 3 \\
10 \cdot 5 \\
9 \cdot 2\end{array}$ \\
\hline Blood transfu & as given on Jul & 21 & & & & \\
\hline $\begin{array}{l}\text { July } 26 \\
\text { Aug. } 11 \\
\text { Aug. } 19 \\
\text { Aug. } 31\end{array}$ & $\begin{array}{l}19,800 \\
16,000 \\
18,500 \\
13,000\end{array}$ & $\begin{array}{r}9,306 \\
8,620 \\
13,470 \\
6,110\end{array}$ & $\begin{array}{r}8,514 \\
28,300 \\
11,100 \\
6,110\end{array}$ & $\begin{array}{l}792 \\
320 \\
370 \\
260\end{array}$ & $\begin{array}{l}\mathbf{0} \\
\mathbf{0} \\
\mathbf{0} \\
\mathbf{0}\end{array}$ & $\begin{array}{l}13 \cdot 7 \\
13 \cdot 4 \\
11 \cdot 9\end{array}$ \\
\hline
\end{tabular}


$50 \mathrm{ml}$. of turbid fluid were withdrawn and 1 mega unit of soluble penicillin was introduced into the pericardial sac. A course of systemic penicillin was begun before completion of the bacteriological sensitivity tests as there was no reason to consider that the organism would be penicillin insensitive.

Cultures of the fluid produced on July 15 a pure growth of coagulase-positive staphylococci. The actual pus was also inoculated on to the routine sensitivity plates and this showed that the staphylococci were insensitive to penicillin and streptomycin, partially sensitive to chlortetracycline and sensitive to chloramphenicol, oxytetracycline, neomycin and erythromycin. In view of the recent administration of chloramphenicol it was felt advisable that systemic therapy should be provided by erythromycin. No preparations of oxytetracycline, neomycin and erythromycin at this time were suitable for local intrapericardial instillation. However, a pharmaceutical firm informed us that they had available a $15 \%$ micronized suspension of chloramphenicol (Sorsby, Unger and Crick, 1953) which it would be safe to instil into the pericardial sac. A supply was dispatched which allowed us to employ locally an effective antibiotic within 24 hours of the initial paracentesis.

Pericardial aspiration produced $70 \mathrm{ml}$. bloodstained turbid fluid, and $8 \mathrm{ml}$. of the $15 \%$ chloramphenicol suspension (1.2 g. chloramphenicol) were introduced.

Pericardial aspiration on July 16 produced $20 \mathrm{ml}$. of fluid, and $8 \mathrm{ml}$. of chloramphenicol suspension were introduced. The fluid still grew a few staphylococci, and the temperature was $100^{\circ} \mathrm{F}$. On examination, there was considerable 'muffling' of the heart sounds, the neck veins were beginning to distend and the liver was enlarged to three fingers below the costal margin. Loculation within the pericardial sac with cardiac compression appeared probable and it was decided to institute open drainage. A chest radiograph confirmed the presence of a large cardiac outline, and a moderate left pleural effusion was also present.

Under general anaesthesia on July 16 a pericardiostomy was performed after resection of 2 in. $(5 \mathrm{~cm}$.) of the seventh left costal cartilage (Donaldson's approach, 1943). Owing to the presence of the pleural effusion, the left pleura was inadvertently opened. Intrapericardial loculations were broken down with the finger and pus and fibrinous clots evacuated, the pus being present under tension. Three fine rubber catheters were inserted, one to the right of the pericardial sac, one to the left and one in the oblique sinus. The parietal pericardium was sutured to the perichondral bed, and the superficial wound lightly packed with tulle gras. The left pleural cavity was drained by an intercostal tube attached to an underwater seal.

Chloramphenicol suspension was instilled daily $(2 \mathrm{ml}$. into each catheter) for six days at the end of which time the catheters were removed: cultures of the pericardial sac were then sterile.

A chest radiograph on July 25 showed that the heart shadow was smaller.

By July 26 the child's temperature was $101^{\circ} \mathrm{F}$. and respirations 40 . There were signs of a fresh left pleural effusion which was confirmed by chest radiographs.

On July 27 pleural aspiration produced $250 \mathrm{ml}$. of yellow, turbid fluid, which proved sterile on culture, but in view of the possibility of pleural contamination at the operation, $4 \mathrm{ml}$. of the chloramphenicol suspension were introduced to the pleural cavity. Aspiration of the pleural cavity and instillation of the chloramphenicol were repeated for the next five days. All cultures of the pleural fluid were sterile.

On August 4 a chest radiograph showed the heart shadow to be slightly smaller; a small area of opacity (? consolidation) in the region of the apical segment of the left lower lobe was seen.

In view of this segmental opacity and the possibility of a metastatic staphylococcal lung abscess, a further course of erythromycin was begun and continued for three weeks.

The child's condition improved steadily and she was eventually discharged on September 1, 1954. She has been reviewed as an out-patient at intervals, and has remained well. The cardiac shadow remains moderately enlarged but the left lung opacity has cleared. There are no signs of chronic cardiac compression. The last radiograph taken on February 15, 1955, showed no change with moderate enlargement of the cardiac shadow.

We are indebted to Mr. A. L. d'Abreu for his advice on the treatment of this child, to Dr. Roy Astley for the radiological examinations, and to the ward sister and nurses for their devoted attention. We are especially grateful to Messrs. Parke, Davis \& Co. for their very generous and extremely prompt assistance in making available to us supplies of the chloramphenicol suspension.

REFERENCES

Aird, Ian (1949). A Companion in Surgical Studies. Edinburgh. d'Abreu, A. L. (1953). A Practice of Thoracic Surgery. London. Donaldson, J. K. (1943). J. thorac. Surg., 12, 209.

Sorsby, A., Ungar, J. and Crick, R. P. (1953). 'Brit. med. J., $2,301$. 